\title{
Leandro Schena, Cécile Desoutter, Claudia Zoratti, Le français en contexte. Réflexion et pratique grammaticales
}

\section{Chiara Preite}

\section{(2) OpenEdition}

\section{Journals}

Édition électronique

URL : http://journals.openedition.org/studifrancesi/36932

DOI : 10.4000/studifrancesi.36932

ISSN : 2421-5856

Éditeur

Rosenberg \& Sellier

Édition imprimée

Date de publication : 1 juillet 2005

Pagination : 218

ISSN : 0039-2944

\section{Référence électronique}

Chiara Preite, « Leandro Schena, Cécile Desoutter, Claudia Zoratti, Le français en contexte. Réflexion et pratique grammaticales », Studi Francesi [En ligne], 145 (XLIX | I) | 2005, mis en ligne le 30 novembre 2015, consulté le 18 avril 2021. URL : http://journals.openedition.org/studifrancesi/36932 ; DOI : https://doi.org/10.4000/studifrancesi.36932

Ce document a été généré automatiquement le 18 avril 2021.

\section{cc) (†) $\odot$}

Studi Francesi è distribuita con Licenza Creative Commons Attribuzione - Non commerciale - Non opere derivate 4.0 Internazionale. 


\title{
Leandro Schena, Cécile Desoutter, Claudia Zoratti, Le français en contexte. Réflexion et pratique grammaticales
}

\author{
Chiara Preite
}

\section{RÉFÉRENCE}

LEANDRO SCHENA, CÉCILE DESOUTTER, CLAUDIA ZORATTI, Le français en contexte. Réflexion et pratique grammaticales, Milano, LED 2003, pp. 246.

1 Cet ouvrage complète le précédent, consacré aux stratégies de lecture de textes spécialisés en Français des affaires. Il s'adresse aux étudiants de niveau universitaire qui désirent approfondir leurs connaissances linguistico-pragmatiques. Le volume est structuré en 11 chapitres dont chacun développe un champ notionnel logique et sémantique: l'expression de la quantité et de l'intensité, de la localisation, du temps, du but, de la cause, de la conséquence, de l'opposition, de la concession et de la restriction, de la condition et de l'hypothèse, de la comparaison, le discours rapporté et les articulateurs logiques du discours. Chaque chapitre présente à l'étudiant un parcours guidé: partant de la section Pages d'ouvertures qui contient une riche série de documents authentiques tirés de typologies textuelles variées visant l'introduction des opérations discursives, le parcours propose des Réflexions sur l'étude des articulateurs logiques et des marqueurs des fonctions discursives dans le but de montrer la connexion profonde entre facteurs syntaxiques, sémantiques et pragmatiques. Le section suivante, Pratique, se compose de batteries d'exercices de manipulation des structures linguistiques et des opérations discursives examinées. Enfin, Traduction permet à l'étudiant de réfléchir sur les aspects contrastifs des deux langues comparées, à travers des textes brefs et variés, 
de caractère littéraire, spécialisé et conversationnel. Les solutions des exercices données en fin de volume permettent un emploi en auto-apprentissage. 